Neurosurg Focus 17 (6):E6, 2004

\title{
Infected vertebroplasty
}

\author{
Report of two cases and review of the literature
}

\author{
David H. Walker, M.D., Praveen Mummaneni, M.D., and Gerald E. Rodts JR., M.D. \\ Department of Neurosurgery, Emory University, Atlanta, Georgia
}

\begin{abstract}
Transpedicular vertebroplasty has been established as a safe and effective treatment for thoracic and lumbar compression fractures. Complications are rare and infectious complications requiring surgical management have only been reported once in the literature. In this paper the authors present two patients in whom osteomyelitis developed after vertebroplasty in which corpectomy was required. The serious nature of these infections, their surgical management, and complication avoidance are discussed.
\end{abstract}

\section{KEY WORDS • vertebroplasty • kyphoplasty • osteomyelitis • polymethyl methacrylate • infection • corpectomy}

Transpedicular vertebroplasty for the treatment of compression fractures of the thoracic and lumbar spine has been well described, and the reported complication rates are low. In this paper we present two cases of patients treated with vertebroplasty despite a history of prior infection. Osteomyelitis and abscess developed in these patients and they underwent corpectomy with anterior reconstruction and posterior stabilization. Great care should be taken when using vertebroplasty to treat patients who have a history of infection, because they may suffer osteomyelitis.

\section{LITERATURE REVIEW}

To identify prior cases of postvertebroplasty osteomyelitis, a Medline search was performed. The key words "vertebroplasty," "kyphoplasty," "infection," and "osteomyelitis" were searched and cross-referenced. Four English-language articles were found in which postvertebroplasty infections were detailed, but only one case report of pyogenic spondylitis following vertebroplasty was identified. The cases of two patients treated at our center are presented.

\section{CASE REPORTS}

\section{Case 1}

History and Examination. This 64-year-old woman had a medical history significant for Type II diabetes mellitus, osteoporosis, and rheumatoid arthritis. She presented at another institution with fevers, acute mental status

Abbreviations used in this paper: $\mathrm{CT}=$ computerized tomography; PMMA = polymethyl methacrylate; $\mathrm{VB}=$ vertebral body. changes, and back pain. A calculus cholecystitis, urinary tract infection, and meningitis were diagnosed and treated. She was also found to have suffered T-11 and T-12 fractures causing back pain.

Three weeks after admission to another hospital she became afebrile and underwent T-11 and T-12 vertebroplasty for treatment of the compression fractures that were causing back pain. The patient again became febrile 11 days after vertebroplasty, and blood cultures and bone biopsy samples of the T-11 vertebra revealed Enterobacter species.

The patient was transferred to our center for further care. Neurologically she was paraparetic, with mild hyperreflexia in the legs. The sagittal CT reconstructions of the thoracolumbar spine (Fig. 1 left) revealed compression fractures of T-11 and T-12 with kyphotic angulation. Axial CT scans demonstrated the presence of PMMA anteriorly in the VB, with retropulsion of bone fragments into the spinal canal (Fig. 1 right).

Operations and Postoperative Course. We performed a thoracoabdominal approach and two-level corpectomy to remove infected PMMA. A titanium mesh cage filled with iliac crest autograft was placed and fixation was obtained with a lateral VB screw-and-rod construct. A second procedure was performed for further stabilization with posterior pedicle screw instrumentation from T-8 to L-3 and posterolateral fusion. Postoperative X-ray films demonstrated improved alignment (Fig. 2). The patient did well postoperatively and was transferred to a rehabilitation facility on a long-term regimen of antibiotic medications.

\section{Case 2}

History and Examination. This 49-year-old woman had undergone discectomies at T-12 and L-1 for discitis 2 years before presentation. Subsequently, a scoliosis devel- 


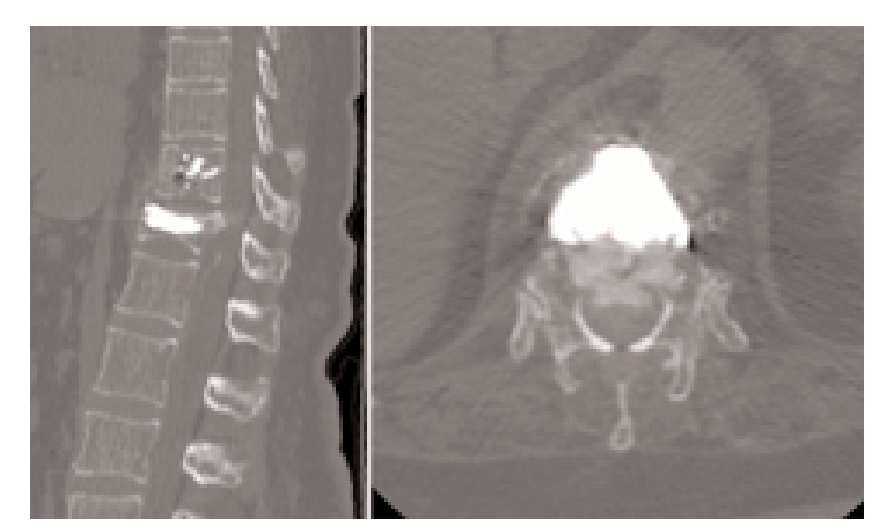

Fig. 1. Case 1. Left: Sagittal reformatted, noncontrasted CT scan demonstrating T-11 and T-12 compression fractures after vertebroplasty. Right: Axial noncontrasted CT scan through T-12 demonstrating retropulsion of bone fragments.

oped and a T-12/L-1 corpectomy and fusion procedure was performed at another hospital. A cage, autograft, and bone morphogenetic protein were placed via a lateral approach. The patient suffered a new L-3 compression fracture postoperatively and underwent vertebroplasty 1 year after her fusion. A CT scan obtained after presentation to our institution 8 months later revealed osteomyelitis at L3 (Fig. 3) and instability.

Operation. The patient underwent an L-3 corpectomy, partial L-2 corpectomy, explantation of hardware, and L2-4 fusion with a Pyramesh cage (Medtronic Sofamor Danek, Memphis, TN) and lateral instrumentation. Tissue cultures revealed coagulase-negative Staphylococcus aureus infection within the L-3 body and on the surface of the vertebroplasty cement. After treatment with antibiotic

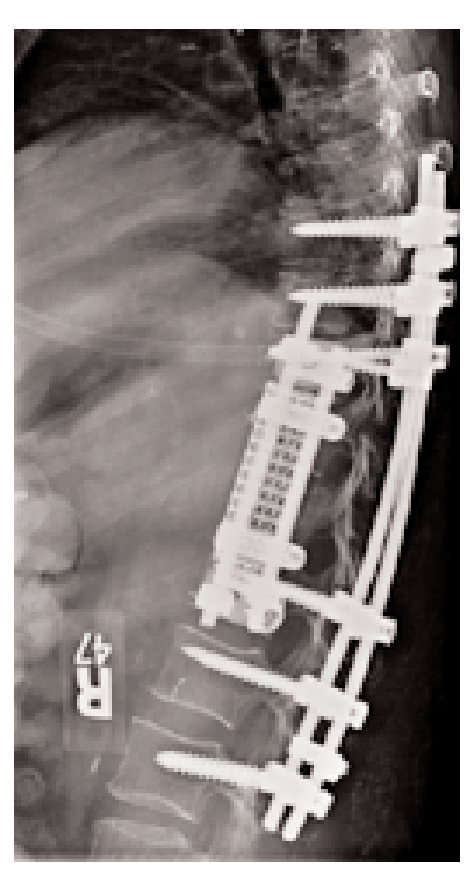

Fig. 2. Case 1. Lateral x-ray film of thoracolumbar spine demonstrating implanted hardware and improved kyphosis.

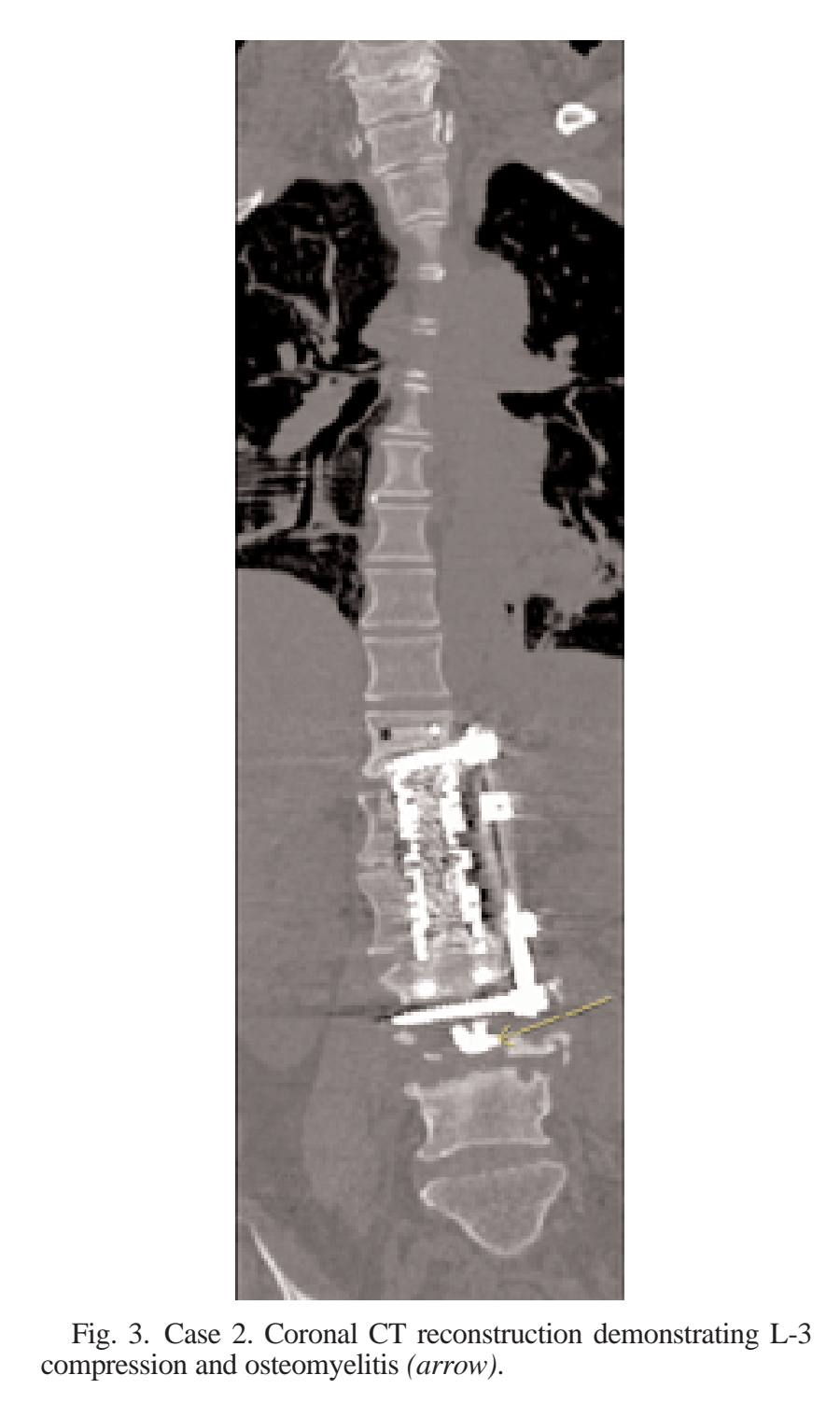

drugs, a supplemental posterior stabilization with a pedicle screw construct was performed from L-2 to L-5.

Postoperative Course. The patient did well postoperatively and was discharged on an antibiotic regimen. Plain $\mathrm{x}$-ray films revealed good alignment and follow-up films obtained 9 months postoperatively demonstrated a developing fusion (Fig. 4). Infectious disease experts recommend that patients such as ours receive lifelong suppressive antibiotic medications.

\section{DISCUSSION}

Percutaneous transpedicular injection of PMMA is a well-established treatment for thoracic and lumbar compression fractures..$^{1-3,5,7,10,14}$ Reported complications include migration of cement into the venous system, neural foramina, and central canal as well as the generation of cement emboli. ${ }^{4,6,8,11,13}$ Infectious complications are generally considered rare. Yu, et al., ${ }^{15}$ report one infection in 200 cases treated. They describe a $6 \%$ complication rate but do not specify which of these were infec-tions, and they re- 


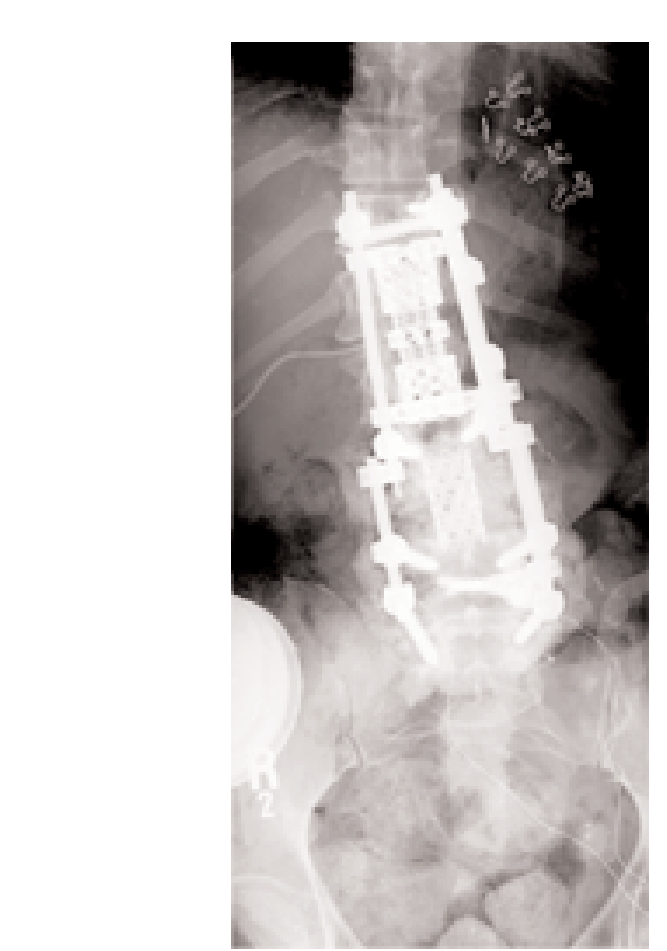

Fig. 4. Case 2. Postoperative anteroposterior x-ray film demonstrating the construct and developing fusion mass.

port a $0 \%$ delayed complication rate. Predey, et al., ${ }^{12}$ declare a complication rate of less than $1 \%$, and Kallmes, et al., ${ }^{9}$ document one infection in $63 \mathrm{VBs}$ treated.

The patient described by $\mathrm{Yu}$, et al., had a urinary tract infection that was treated with intravenous antibiotic drugs before the vertebroplasty was performed. Our two patients also had previous infections. The patient in Case 1 had a preexisting urinary tract infection as well as recent sepsis. She had received antibiotic medications for several weeks before the vertebroplasty. The patient in Case 2 had undergone previous discectomies for discitis. The delayed nature of her subsequent osteomyelitis is unusual. These infections resulted in the patients undergoing extensive anterior and posterior surgeries for debridement and stabilization. Vertebroplasty is a procedure for which a low complication rate has been established, although patients with any history of infection should be treated with great caution.

\section{CONCLUSIONS}

Patients who undergo vertebroplasty should be definitively screened for systemic infection before treatment. The results of an infectious complication can be severe. Perhaps infection prophylaxis, such as the use of cement mixed with antibiotic drugs or a prolonged postprocedure antibiotic regimen, should be considered in patients whom the physician feels compelled to treat with vertebroplasty despite recent infection.

\section{References}

1. Belkoff SM, Mathis JM, Jasper LE, et al: The biomechanics of vertebroplasty. The effect of cement volume on mechanical behavior. Spine 26:1537-1541, 2001

2. Chiras J, Sola-Martinez MT, Weill A, et al: [Percutaneous vertebroplasty.] Rev Med Interne 16:854-859, 1995 (Fre)

3. Cotten A, Dewatre F, Cortet B, et al: Percutaneous vertebroplasty for osteolytic metastases and myeloma: effects of the percentage of lesion filling and leakage of methyl methacrylate at clinical follow-up. Radiology 200:525-530, 1996

4. Garfin SR, Yuan HA, Reiley MA: New technologies in spine: kyphoplasty and vertebroplasty for the treatment of painful osteoporotic compression fractures. Spine 26:1511-1515, 2001

5. Harrington KD: Major neurological complications following percutaneuous vertebroplasty with polymethylmethacrylate: a case report. J Bone Joint Surg Am 83:1070-1073, 2001

6. Jensen ME, Evans AJ, Mathis JM, et al: Percutaneous polymethylmethacrylate vertebroplasty in the treatment of osteoporotic vertebral body compression fractures: technical aspects. AJNR 18:1897-1904, 1997

7. Kallmes DF, Schweickert PA, Marx WF, et al: Vertebroplasty in the mid- and upper thoracic spine. AJNR 23:1117-1120, 2002

8. Lieberman IH, Dudeney S, Reinhardt MK, et al: Initial outcome and efficacy of "kyphoplasty" in the treatment of painful osteoporotic vertebral compression fractures. Spine 26:1631-1638, 2001

9. Moreland DB, Landi MK, Grand W: Vertebroplasty: techniques to avoid complications. Spine J 1:66-71, 2001

10. O'Brien JP, Sims JT, Evans AJ: Vertebroplasty in patients with severe vertebral compression fractures: a technical report. AJNR 21:1555-1558, 2000

11. Padovani B, Kasriel O, Brunner P, et al: Pulmonary embolism caused by acrylic cement: a rare complication of percutaneous vertebroplasty. AJNR 20:375-377, 1999

12. Predey TA, Sewall LE, Smith SJ: Percutaneous vertebroplasty: new treatment for vertebral compression fractures. Am Fam Physician 66:611-615, 2002

13. Ratliff J, Nguyen T, Heiss J: Root and spinal cord compression from methylmethacrylate vertebroplasty. Spine 26: E300-E302, 2001

14. Tohmeh AG, Mathis JM, Fenton DC, et al: Biomechanical efficacy of unipedicular versus bipedicular vertebroplasty for the management of osteoporotic compression fractures. Spine 24: 1772-1776, 1999

15. Yu SW, Chen WJ, Lin WC, et al: Serious pyogenic spondylitis following vertebroplasty—a case report. Spine 29:E209-E211, 2004

Manuscript received October 15, 2004.

Accepted in final form November 4, 2004.

Address reprint requests to: Gerald E. Rodts Jr., M.D., Department of Neurosurgery, Emory University, 550 Peachtree Street, Suite 806, Atlanta, Georgia 30308-2247. email: gerald_rodts@ emoryhealthcare.org. 